\title{
Passage of indigestible particles of various specific gravities in sheep and goats
}

\author{
BY K. KATOH, F. SATO, A. YAMAZAKI, Y. SASAKI AND T. TSUDA \\ Department of Animal Physiology, Faculty of Agriculture Tohoku University, \\ Tsutsumidori Amamiyamachi, Sendai 980, Japan
}

(Received 21 July 1987 -Accepted 26 July 1988)

\begin{abstract}
1. Eight kinds of indigestible particles with specific gravities (SG) ranging from 0.92 to 1.87 ( $2 \mathrm{~mm}$ diameter and $4 \mathrm{~mm}$ length) were injected into the reticulo-rumen of sheep and goats in order to investigate the relation between SG and passage through the gastrointestinal tract, and the difference in passage time in the two species of animals.

2. The percentage of excreted particles significantly increased, while the percentage of ruminated particles in the excreted particles significantly decreased, as the SG increased.

3. The daily and cumulative recovery rates of particles of SG 1.38 were slower in sheep than in goats, while those with SG 0.92 were not different between species.

4. It is concluded that particles with SG higher than $1 \cdot 27$ would pass through the gastrointestinal tract of sheep and goats more quickly than those with SG lower than $1 \cdot 21$.
\end{abstract}

Many studies have been made of the time of passage of forage particles through the digestive tract of ruminant animals in relation to specific gravity (SG), size and shape, because these physical characteristics are important in regulating roughage digestibility and intake (Kennedy, 1984; Faichney, 1986). The use of diets treated to reduce degradation in the reticulo-rumen has also led to studies using indigestible particles (King \& Moore, 1957; Campling \& Freer, 1962; Derrickson et al. 1965; desBordes \& Welch, 1984; Hooper \& Welch, 1985). It is found in cattle that particles with an SG of about 1.2 pass out of the reticulo-rumen more quickly than those with lower SG.

In the present study, we injected eight kinds of indigestible particles, varying in SG, into the reticulo-rumen of sheep and goats in order to find the SG of particles which pass more quickly through the digestive tract (especially the stomachs) and to establish the difference in passage time in the two species of animals. This kind of experiment could provide information on (1) the optimal SG of the artificial materials containing nutrients or drugs which are obstructive or easily inactivated by ruminal microbes, but useful for animal production when digested and absorbed in the lower gut, and (2) on the species difference in passage time due to ruminant feeding types.

\section{MATERIALS AND METHODS}

Four crossbred Merino sheep (three female and one castrated male, $35-50 \mathrm{~kg}$ ) and four female Saanen goats $(39-59 \mathrm{~kg})$ were used. They were housed in metabolism cages at an air temperature of $20 \pm 2^{\circ}$, and fed on lucerne (Medicago sativa) hay cubes $(20 \mathrm{~g} / \mathrm{kg}$ bodyweight) at 09.00 hours. They had free access to water.

The indigestible particles of a mixture of polycarbonate and polyethylene were injected as a suspension in tap water $(100 \mathrm{ml})$ into the reticulo-rumen through a polyethylene stomach tube introduced into the reticulo-rumen (500 of each particle). The SG of the particles used were $0.92,1.09,1.21,1.27,1.38,1.45,1.68$ and 1.87. The SG was varied by adjusting the polycarbonate:polyethylene ratio. The particles were all of the same rodshape and size ( $2 \mathrm{~mm}$ diameter and $4 \mathrm{~mm}$ length), but differed in colour. Faeces were collected every day just before feeding time for $10 \mathrm{~d}$ after the reticulo-rumen injection. 


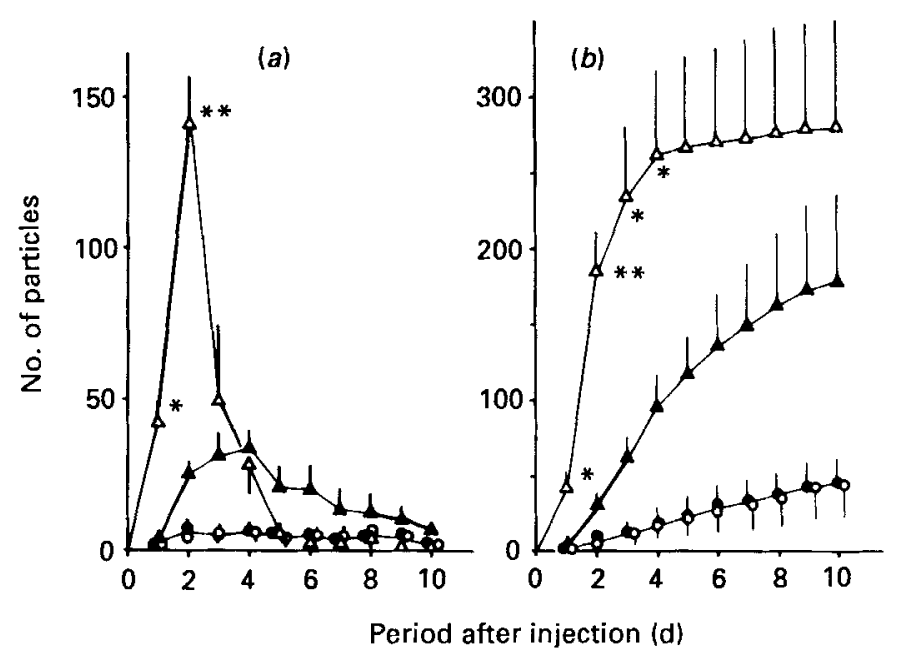

Fig. 1. The typical ( $a$ ) daily and $(b)$ cumulative recoveries of indigestible particles (specific gravities 0.92 $(O, \bullet)$ and $1.38(\Delta, \Delta))$ excreted in faeces of sheep $(\boldsymbol{\Delta}, \boldsymbol{\Delta})(n 4)$ and goats $(O, \square)(n 4)$ during $10 \mathrm{~d}$ following a single reticulo-rumen injection (500 of each particle). Points are means with their standard errors represented by vertical bars. Significant differences between values for sheep and goats at the same specific gravity (non-paired $t$ test): ${ }^{*} P<0.05,{ }^{* *} P<0.01$.

Particles in the faeces were collected as follows. Each 24 -h faecal sample was placed in a nylon-mesh bag (mesh size $1.6 \times 1.6 \mathrm{~mm}$ ) and soaked in tap water for about $3 \mathrm{~h}$. The particles were then picked out one by one from the bag using tweezers, their SG being indicated by their colour. The number of ruminated particles was also counted. They were identified by teeth marks on the surface or deformation, or both.

\section{Statistical analysis}

The results are shown as the means and standard errors of the means. Paired $t$ tests were used to compare the different specific gravities within each animal species, and unpaired (Aspin-Welch/Student) $t$ tests to compare the two species at the same SG. Spearman's rank correlation test was used to examine the correlation between proportion recovered and specific gravities in each animal species (Zar, 1984).

\section{RESULTS}

The daily recovery (real number of particles excreted) and the cumulative recovery of particles (SG 0.92 and 1.38) during $10 \mathrm{~d}$ following a single reticulo-rumen injection into sheep and goats are shown in Fig. 1.

In the case of the SG 0.92 particles, the daily and cumulative recoveries from sheep and goats were very small, and there was no significant difference between animal species. However, in the case of the particles of SG 1.38, the daily recovery of particles from sheep and goats had a peak value on days 4 and 2 respectively. The daily recovery of the SG 1.38 particles was significantly larger than those of the SG 0.92 particles on days 2 to 4 in sheep and on days 1 and 2 in goats.

The cumulative recovery of the SG 1.38 particles was significantly larger than that of the SG 0.92 particles on days $2-10$ in sheep and on all days in goats.

The cumulative recovery rate ( $\%$ of the number injected) and the percentage of 

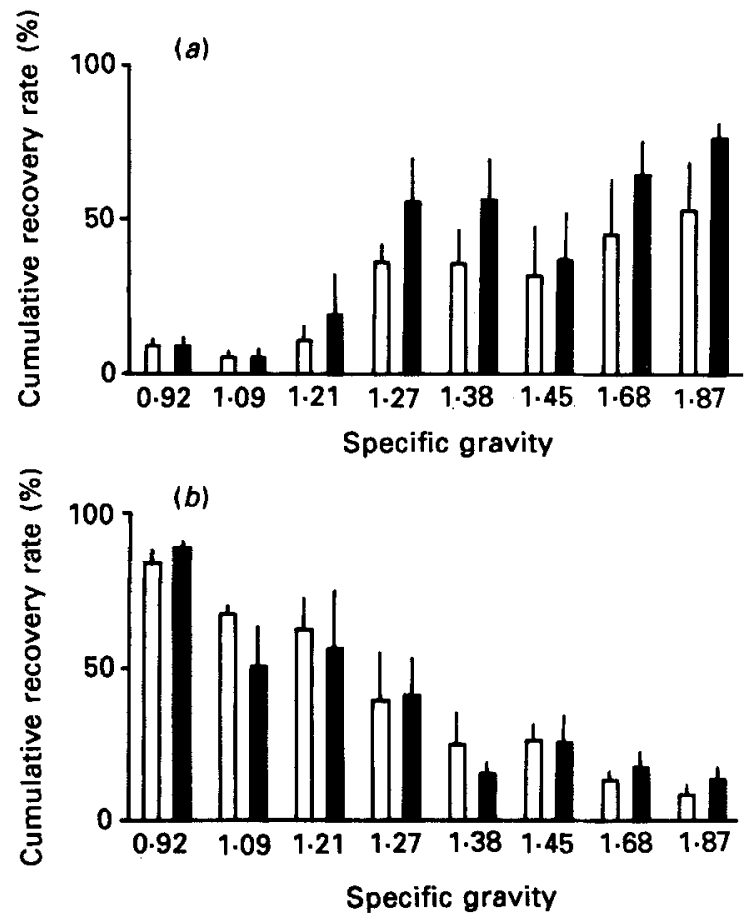

Fig. 2. The cumulative recovery rates of $(a)$ total excreted ( $\%$ of number injected) and $(b)$ ruminated $(\%$ of the total number recovered) particles of a range of specific gravities in sheep ( $\square)(n 4)$ and goats $(\square)$ ( $n$ 4) on day 10 after a single reticulo-rumen injection (500 of each particle). Values are means with their standard errors represented by vertical bars. The correlations between portions and specific gravities in the two species of animals were significant (by Spearman's rank correlation test): $P<0.01$.

ruminated particles in the excreted particles on day 10 after reticulo-rumen injection are presented in Fig. 2.

The cumulative recovery rate of particles gradually and significantly $(P<0.01)$ increased with increasing SG in both animal species $(r 0.5766$ and 0.6888 in sheep and goats respectively). The maximal recoveries in sheep and goats, which were obtained with the heaviest particle (SG 1.87), were 52.7 (SE 16.5) and 75.8 (SE 5.1) \% respectively. The particles with lower SG $(0.92,1.09$ and 1.21$)$ were recovered to only a small extent (less than $20 \%)$ and significantly smaller than that of the SG 1.27 particles in both animal species. There was, however, no significant difference between animal species at any SG.

The percentage of ruminated particles in the excreted particles decreased significantly $(P<0.01)$ with increasing SG in both animal species $(r-0.8218$ and -0.6992 in sheep and goats respectively). The maximal percentages of ruminated particles in sheep and goats, which were obtained with the lightest particle (SG 0.92), were 83.2 (SE 4.5) and 88.2 (SE 2.8 ) \% respectively. There was no significant difference between animal species at any SG.

\section{DISCUSSION}

It has already been reported that plastic and rubber particles with SG higher than 1.20 pass through the digestive tract in cattle faster than particles of lower SG and that the latter are ruminated more readily than particles of higher SG (King \& Moore, 1957; Campling \& Freer, 1962; Derrickson et al. 1965; desBordes \& Welch, 1984; Hooper \& Welch, 1985). 
Our present results in sheep and goats are essentially compatible with the results obtained in cattle. Furthermore, it is likely that the critical SG in particles of this size might be between 1.21 and 1.27 in these animal species, since particles of SG lower than 1.21 were excreted significantly less quickly than the SG 1.27 particles.

The finding in sheep and goats that the percentage of excreted particles increased but the percentage of the ruminated particles in the excreted particles decreased as the SG of particles increased agrees with the results reported in cattle by desBordes \& Welch (1984). It seems that the particles with SG lower than 1.21 were almost completely retained in the reticulo-rumen and ruminated, since our preliminary findings, not reported here in detail, showed that the particles with SG lower than 1.21 were rapidly eliminated from the intestines when injected into the duodenum of sheep, while the SG 0.92 particles remained in the reticulo-rumen even on day 10 after the reticulo-rumen injection, and nearly $90 \%$ of them had been ruminated.

Faichney (1975) reported the mean retention time in the whole digestive tract of sheep to be $73 \mathrm{~h}$, which was similar to $70 \mathrm{~h}$ obtained by the same method by Van Soest $(1982 \mathrm{a})$. On the other hand, Castle (1956) and Van Soest (1982a) obtained mean retention times of 38 and $52 \mathrm{~h}$ respectively in Sannen goats. We estimated, by Faichney's (1975) method, the approximate mean retention times from the cumulative excretion curves of the indigestible particles in both animal species (Fig. 1, SG, 1.38). The values were 92 and $48 \mathrm{~h}$ in sheep and goats respectively. It is likely that the passage times in both animal species obtained in the present study are similar to those reported and that the mean retention time in sheep is longer than that in goats.

While the difference in retention time between sheep and goats cannot yet be explained, the classification of ruminant animals proposed by Hofmann (1973) may suggest a possible explanation. He classified ruminant species into three types from the structure of their stomachs and other features, namely roughage eaters (grazers), concentrate selectors (browsers) and intermediate adaptable feeders. The concentrate selectors have a smaller reticulo-rumen and shorter food retention time, while roughage eaters have a larger reticulo-rumen and longer food retention time. Longer retention time may be of advantage to fibre digestibility (Van Soest, 1982 b). Goats belong to the intermediate group, while sheep belong to roughage eaters (see Kay et al. 1980). This classification would partly explain the difference in results between sheep and goats, and the difference may be associated with the movements of the reticulo-omasal orifice and reticulo-rumen as well as their relative sizes (Deswysen, 1987; Kay, 1987).

We used sheep of both sexes (female and castrated male sheep) and female goats. However, we found in a preliminary experiment that sex, presence or absence of a ' $T$ 'shaped duodenal cannula, and body-weight of sheep $(35-50 \mathrm{~kg})$ did not cause a significant difference in the daily or cumulative recovery of the particles with SG of 1.27 . Therefore, it is unlikely that there was any difference between female and castrated male sheep used in the present experiment.

The present results suggest that the SG of particles is the important factor limiting passage from the reticulo-rumen. However, our findings would only account for a small fraction of normal particulate matter in faeces since the particle size in faeces was less than $1 \mathrm{~mm}$ in sheep and goats (Grenet et al. 1984), although it was also reported that particles with a length less than $6 \mathrm{~mm}$ flowed through the reticulo-omasal orifice and omasum in sheep (Hauffe \& von Engelhardt, 1975).

The authors gratefully acknowledge Dr R. N. B. Kay (Rowett Institute) for his criticism and help in preparing this manuscript. The particles were kindly donated by Showa Denko Co., Japan. This work was in part supported by a Grant-in-Aid for Scientific Research from The Japanese Education Ministry (no. 61760222) and Showa Denkn $C_{n}$ 


\section{REFERENCES}

Campling, R. C. \& Freer, M. (1962). British Journal of Nutrition 16, 507-518.

Castle, E. J. (1956). British Journal of Nutrition 10, $15-23$.

Derrickson, C. M., Hoefer, J. A., Bradley, N. W., Ullrey, C. M. \& Little, C. O. (1965). Journal of Animal Science 24, 879.

desBordes, C. K. \& Welch, J. G. (1984). Journal of Animal Science 59, 470 475.

Deswysen, A. G. (1987). In Physiological and Pharmacological Aspects of the Reticulorumen, pp. 133-154 [L. A. A. Ooms, A. D. Degryse and A.S. J. P. A. M. van Miert, editors]. Dordrecth: Martinus Nijhoff Publishers.

Faichney, G. J. (1975). Australian Journal of Agricultural Research 13, 319-327.

Faichney, G. J. (1986). In Control of Digestion and Metabolism in Ruminants, pp. 173-195 [L. P. Milligan, W. L. Grovum and A. Dobson, editors]. New Jersey: A. Reston Books.

Grenet, E., Martin-Rosset, W. \& Chenost, M. (1984). Canadian Journal of Animal Sciences 64 Suppl., 345-346.

Hauffe, R. \& von Engelhardt, W. (1975). Zentralblatt für Veterinarmedizin 22, 149-163.

Hofmann, R. R. [editor] (1973). The Ruminant Stomach, East African Monographs in Biology, vol. 2. Nairobi : East African Literature Bureau.

Hooper, A. P. \& Welch, J. G. (1985). Journal of Dairy Science 68, 1181-1188.

Kay, R. N. B. (1987). In Physiological and Pharmacological Aspects of the Reticulorumen, pp. 155-170 [L. A. A. Ooms, A. D. Degryse and A. S. J. P. A. M. van Miert, editors]. Dordrecht: Martinus Nijhoff Publishers.

Kay, R. N. B., von Engelhardt, W. \& White, R. G. (1980). In Digestive Physiology and Metabolism in Ruminants, pp. 743-761 [Y. Ruckebusch and P. Thivend, editors]. Lancaster: MTP Press.

Kennedy, P. M. [editor] (1984). Techniques in Particle Size Anaysis of Feed and Digesta in Ruminants, Canadian Society of Animal Science, Occasional Publication, no. 1. Edmonton: Canadian Society of Animal Science.

King, K. W. \& Moore, W. E. C. (1957). Journal of Dairy Science 40, 528-536.

Van Soest, P. J. [editor] (1982a). In Nutritional Ecology of the Ruminant, pp. 211-229. Corvallis: O. \& B. Books.

Van Soest, P. J. [editor] (1982 b). In Nutritional Ecology of the Ruminant, pp. 325-344. Corvaliis: O. \& B. Books.

Zar, J. H. [editor] (1984). Biostatistical Analysis, 2nd ed. Englewood Cliffs: Prentice-Hall. 